\title{
Implementing a multi-vehicle multi-route spatial decision support system for efficient trash collection in Portugal
}

\author{
Luís Santos $^{\mathrm{a}, \mathrm{c}}$, João Coutinho-Rodrigues ${ }^{\mathrm{a}, \mathrm{c}}$, John R. Current ${ }^{\mathrm{b}, *}$ \\ ${ }^{a}$ Department of Civil Engineering, Faculty of Sciences and Technology, Polo II, University of Coimbra, 3030-788 Coimbra, Portugal \\ ${ }^{\mathrm{b}}$ Department of Management Sciences, The Fisher College of Business, The Ohio State University, \\ 632 Fisher Hall, 2100 Neil Avenue, Columbus, OH 43210-1144, USA \\ ${ }^{\mathrm{c}}$ INESC-Coimbra, R. Antero Quental, 199, 3000-033 Coimbra, Portugal
}

Accepted 21 August 2007

\begin{abstract}
More efficient vehicle routing can improve a firm's competitive advantage or increase the efficiency by which governmental agencies supply public services. More efficient routing can also reduce traffic congestion and air pollution which are growing problems in many urban areas. Unfortunately, the identification of the optimal solution to most vehicle routing problems is computationally intractable. This article presents a user-friendly spatial decision support system (SDSS) to generate vehicle routes for multiple-vehicle routing problems that serve demand located along arcs and at nodes of the transportation network. The SDSS incorporates a geographical information system (GIS) and heuristic solution procedures to generate routes, system-wide data, and maps, as well as individual vehicle route maps, directions, and data quickly. It accommodates realistic system specifics such as vehicle capacity and time constraints and network constraints such as one-way streets, and prohibited turns. The system was tested for trash collection in Coimbra, Portugal. In addition, the SDSS can be used for "what-if" analysis related to possible changes to input parameters such as vehicle capacity and maximum driving time.
\end{abstract}

(C) 2008 Elsevier Ltd. All rights reserved.

Keywords: Vehicle routing; Spatial decision support systems; Geographical information systems; Heuristics

\section{Introduction}

The transportation of goods and services imposes considerable costs on both the public and private sectors of the economy. In cities, the movement of goods may account for $20-30 \%$ of the total vehicle miles traveled and for 16-50\% of all air pollutants resulting from transportation (Dablanc, 2007). Dablanc's article, "Goods transport in large European cities: difficult to organize, difficult to modernize", calls for improved logistics in

\footnotetext{
* Corresponding author. Tel.: +1 614292 3166; fax: +1 614292127.

E-mail addresses: 1santos@dec.uc.pt (L. Santos), coutinho@dec.uc.pt (J. Coutinho-Rodrigues), current.1@osu.edu (J.R. Current).
} 
European cities. Improved logistics also would benefit the United States of America where freight transportation costs account for approximately $6 \%$ of the GDP (MacroSys Research and Technology, 2005). Unfortunately the optimization of transportation routing is computationally intractable for most real-world problems (e.g., Garey and Johnson, 1979; Magnanti and Wong, 1984). As a consequence, the design and implementation of exact and heuristic solution algorithms for such problems have been important research streams in the field operations research (OR).

Due to the data requirements and the complexity of transportation problems, there has been a growing interest in the use of decision support systems (DSS) to analyze them from the operational level (e.g., Simao et al., 2004; Maria et al., 2005) to the strategic planning level (e.g., Coutinho-Rodrigues et al., 1997; Úlengin et al., 2007). GIS is a natural component of such systems as it is an important tool for collecting, organizing, and displaying spatial data. It is also an effective way to enter data into mathematical models as well as to present the results of such models to decision makers (Church, 2002). Although transportation research has been "late to embrace GIS as a key technology to support its research and operational needs" (Thill, 2000), there has been an increase of such research in recent years. Much of this research also incorporates exact and heuristic solution algorithms with the GIS in what are referred to as spatial decision support systems (e.g., Coutinho-Rodrigues et al., 1997; Simao et al., 2004; Jha and Schonfeld, 2004; Maria et al., 2005; AlçadaAlmeida et al., in press).

In this article, we present a spatial decision support system (SDSS) designed to increase the efficiency of multiple-vehicle routing problems. The SDSS was designed for, and tested on, a real-world multiple-vehicle routing problem: trash collection in the City of Coimbra, Portugal. Although the application presented in this paper is specific, the GIS-based SDSS is applicable to many public and private sector multiple-vehicle routing problems. The system can be used for short-term analysis (e.g., the design of daily vehicle routes) and longterm analysis (e.g., how many vehicles to operate).

The Coimbra transportation system managers imposed several important design criteria for the GIS-based SDSS. First, it must generate efficient solutions (i.e., vehicle collections routes) quickly as demand patterns and routes can change daily. Second, the system must be easy to use for people with little or no background in operations research or GIS. Third, it must be able to incorporate system data easily from existing spreadsheet data files. Fourth, the SDSS must generate individual route maps and directions for the drivers. Finally, the system must be able to incorporate various local network specific conditions and constraints. It was also desirable for the system to be able to analyze long-term decisions such as the number (and/or size) of vehicles to operate and the length of an employee's work shift.

The remainder of this article is organized as follows. Background information is presented in the next section. Specifics of the SDSS application are given in the third section and a summary and conclusion are presented in the last section.

\section{Problem background}

Vehicle routing is a common and costly problem faced by many private and public sector enterprises. Two of the most basic vehicle routing problems are the traveling salesman problem (TSP) (Dantzig et al., 1954) and the Chinese postman problem (CPP) (Kwan, 1962). The TSP identifies the least cost route of a single vehicle that includes (i.e., serves demand on) every node in the network and then returns to the starting node. Unfortunately, this very basic routing problem belongs to the set of NP-hard problems (Garey and Johnson, 1979). The CPP identifies the least cost route of a single vehicle that includes (i.e., serves demand on) every arc in the network. The CPP can be solved in polynomial time (e.g., Christofides, 1973).

Several assumptions underlie the TSP and the CPP that are not realistic for many practical vehicle routing problems. For example, they both assume that the vehicle (or sales person) has no load (or time) capacity constraint. Consequently, a single route can serve all of the demand. The addition of vehicle capacity constraints to the CPP results in the capacitated CPP which is a NP-hard problem (e.g., Golden and Wong, 1981). Second, they assume that demand exists at every node in the network (TSP) or along every arc of the network (CPP). These assumptions are not appropriate for many vehicle routing problems. Unfortunately, relaxing these assumptions make the problems more difficult to solve. 
The problem most closely resembling the one at hand is the capacitated arc routing problem (CARP) introduced by Golden and Wong (1981). In this problem demand occurs along the arcs, some arcs in the network may not require service (i.e., have no demand along them) and the vehicles have a capacity on the total demand that they can serve. Golden and Wong (1981) proved that CARP belongs to the class of NP-hard problems.

Coimbra's trash collection problem cannot be solved as a CARP because of various network specific conditions/constraints that complicate the vehicle routing problem. We refer to the Coimbra routing problem as the constrained CARP or C-CARP. These network specific conditions/constraints that differentiate C-CARP from CARP include:

1. One-way streets (i.e., network includes directed arcs).

2. Demand at network nodes (i.e., intersections) as well as along the arcs. For example, when a trash collection vehicle in Coimbra arrives at a street intersection, it may collect trash from all of the buildings at that intersection during one stop. Clearly nodes are on arcs so CARP will serve them. However, defining demand at nodes increases the flexibility of the routing decision as this demand may be served by any arc that enters it.

3. Prohibited turns (e.g., U-turns and left turns) at various network intersections.

4. Demand along arcs (i.e., streets) that are too narrow for standard-sized vehicles to traverse.

5. Vehicles can serve more than one route in a day. All routes for a particular vehicle must include a "drop-off point" (i.e., landfill in this case) that is not the starting depot. Only the last route for each vehicle must return to the starting depot immediately after visiting the "drop-off point".

6. The time to serve all of a vehicle's routes (in a day) must be less than the maximum hours that the vehicle's crew can work that day.

Given the similarity of Coimbra's trash collection problem to the CARP, CARP solution procedures appeared to be good starting places to develop a solution procedure for C-CARP. Several heuristic solution procedures have been developed to solve the CARP. These include "construct and strike" (Christofides, 1973; Golden et al., 1983), "modified construct and strike" (Pearn, 1984), "augment and merge" (Golden and Wong, 1981; Golden et al., 1983), "path scanning" (Golden et al., 1983), and "parallel insertion" (Chapleau et al., 1984).

We decided to solve C-CARP using a modified version of the path-scanning (Golden et al., 1983). This decision was based on a comparative study of the heuristics (Coutinho-Rodrigues et al., 1993), which found that the path-scanning heuristic was faster than the others, used less memory, and produced good solutions that averaged about $10 \%$ above the lower bound in the tested problems. In addition, the path-scanning heuristic could be modified to include the problem differences between CARP and C-CARP mentioned earlier.

The path-scanning heuristic with five criteria constructs one route at a time in a "greedy-add" fashion. The algorithm is executed five times with each execution using a different decision criterion. During each run, individual routes are built one arc at a time (the shortest path is used to connect two consecutive arcs and/or nodes serviced if they are not adjacent). This is done by adding the best arc (for the current decision criterion) until the vehicle capacity is exhausted. When the vehicle's capacity is exhausted, the algorithm returns the vehicle to the "drop-off point" (landfill in our case) via the shortest path through the network. The solutions generated by the five criteria are compared and the best solution is selected.

To describe the five arc selection criteria, we assume that a route is at some node $i$ and we want to determine which arc $(i, j)$ should be the next arc on the route. The selection criteria are to select the arc $(i, j)$ such that: (1) the ratio of the distance of the arc, $c_{i j}$, to the demand on the arc, $d_{i j}$, is minimized; (2) the ratio of the distance of the arc, $c_{i j}$, to the demand on the arc, $d_{i j}$, is maximized; (3) the distance from node $j$ back to the landfill is minimized; (4) the distance from node $j$ back to the landfill is maximized; and (5) if the vehicle is less than halffull use criterion 4 , otherwise use criterion 3 .

The routing heuristic employed by the SDSS utilizes the basic structure (and five criteria) of Golden et al. (1983). However, numerous modifications were necessary to incorporate the network specific conditions/constraints mentioned earlier. For example, the shortest path algorithm (Dijkstra, 1959) embedded in the Golden et al. (1983) heuristics had to be modified to incorporate the "turn restrictions" of the problem at hand. This modification is similar that presented in Namkoong et al. (1998) and used by other authors (e.g., Lacomme et al., 2004; Belenguer et al., 2006), and is explained in Appendix. 


\section{Implementation of C-CARP in a GIS-based SDSS}

The design criteria for the SDSS for the Coimbra trash collection problem were stated earlier. In summary, the Coimbra planners had certain input and output requirements as well as desired analytical/planning capabilities. These included the ability to: generate "good" solutions and allow system planners to alter these routes manually; generate maps and instructions for individual vehicle routes and system solutions; and import/export data via spreadsheet files.

To achieve these objectives, the SDSS needed data/information management/analysis capabilities and graphical display capabilities. Given these requirements and the "spatial" nature of the data, a SDSS that incorporated GIS seemed most appropriate. Consequently, the SDSS for this multi-stop, multi-vehicle routing was implemented in Avenue, an object-oriented language included in ESRI's ArcView version 3.

C-CARP was tested in the urban core of the City of Coimbra; a Portuguese city of about 120,000 inhabitants. The sanitation department of Coimbra collects trash on approximately $1900 \mathrm{~km}$ of streets. The collection region with the highest per area demand and the most complex routing options is the urban core of this network presented in Fig. 1.

\subsection{SDSS input}

Problem parameters such as arc and node service demand, arc traversal times, vehicle capacities, and constraints such as turn prohibitions and the maximum time a vehicle (crew) can operate in a day can be edited in the SDSS environment via dialogue boxes like the one shown in Fig. 2 or in a spreadsheet and then imported into the SDSS. In the Coimbra example, there are 20 nodes where demand could be served regardless of the arc used to enter the node (i.e., nodes with demand) and 45 nodes with turn restrictions. The former nodes are represented in Fig. 1 with circles and the latter are identified with triangles.

Trash collection in Coimbra has two additional constraints that demonstrate the flexibility of C-CARP and the SDSS used to implement it. First, the City of Coimbra is approximately 2000 years old; consequently, streets in some sections of the city are too narrow for standard-sized vehicles that have a capacity of $7000 \mathrm{~kg}$. Demands at arcs and nodes in these areas are served via one of two predetermined methods. In

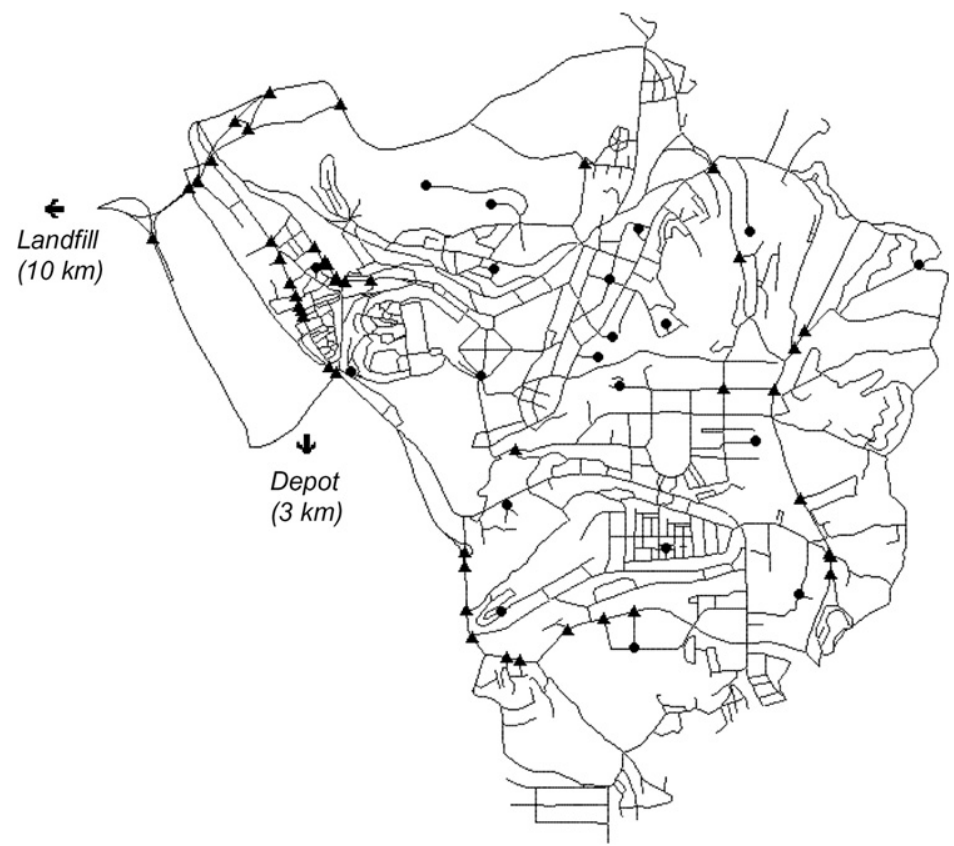

Fig. 1. Coimbra street network with nodes with prohibited turns (triangles) and demand (circles) indicated. 


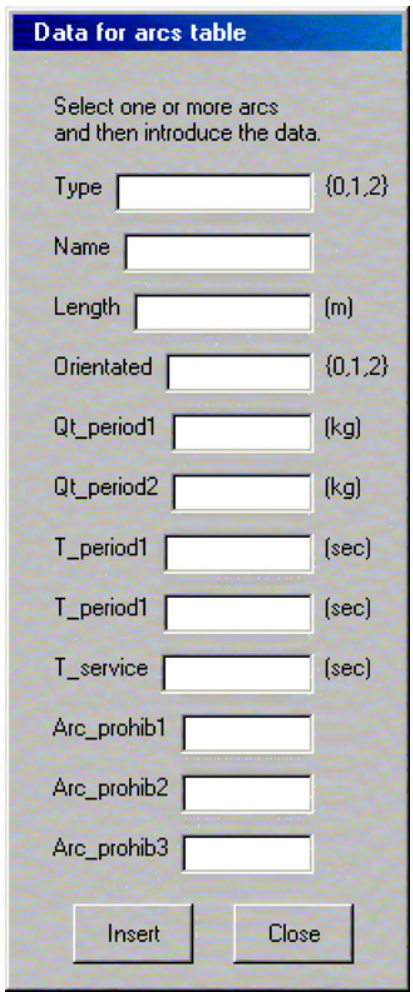

Fig. 2. Network data entry dialog box.

the first method, the trash is hauled manually to an arc that can accommodate a standard vehicle and is counted as part of that arc's demand. This method is used for extremely narrow streets. The second method identifies a subnetwork of narrow streets that can be served by a vehicle of smaller capacity (i.e., $400 \mathrm{~kg}$ ). The arcs in this subnetwork can be labeled by "clicking" on them or by enclosing them in a mouse drawn box on the network. After such arcs have been labeled, only the smaller capacity vehicles can traverse them. However, these smaller vehicles may use any of the "standard-sized" streets in their routes. Fig. 3 highlights a "neighborhood" of such narrow streets in Coimbra.

A "route" for a vehicle is constrained by the volume of trash it can carry (i.e., vehicle capacity) and the time it takes to service the route (maximum employee shift time). A vehicle may serve more than one route in a day as long as the total routing time for the vehicle is less than the maximum employee shift time. The routing heuristic embedded in the SDSS enforces both the vehicle capacity and total service time constraints for each vehicle.

The situation in Coimbra is additionally complicated by the fact that the route "drop-off point" (a landfill) is not at the same location as the depot where the vehicles start and end their shifts. The first route starts at the depot and all routes must go to the landfill when completed. However, only the last route in a given vehicle's shift must return to the starting depot. The routing heuristic embedded in the SDSS incorporates these network specifications.

\subsection{SDSS output}

The primary output of the SDSS is the design of efficient vehicle routes. The SDSS determines the number of vehicles and routes, as well as designs the individual routes. Additional output includes system-wide data, and maps and individual vehicle data and maps. The problem was solved initially with a $7 \mathrm{~h} 30 \mathrm{~min}$ shift limit, which reflects current policy. Summary system-wide and individual vehicle information for this solution is presented in Table 1. The solution requires five shifts (i.e., vehicles) to serve nine routes. A system-wide 


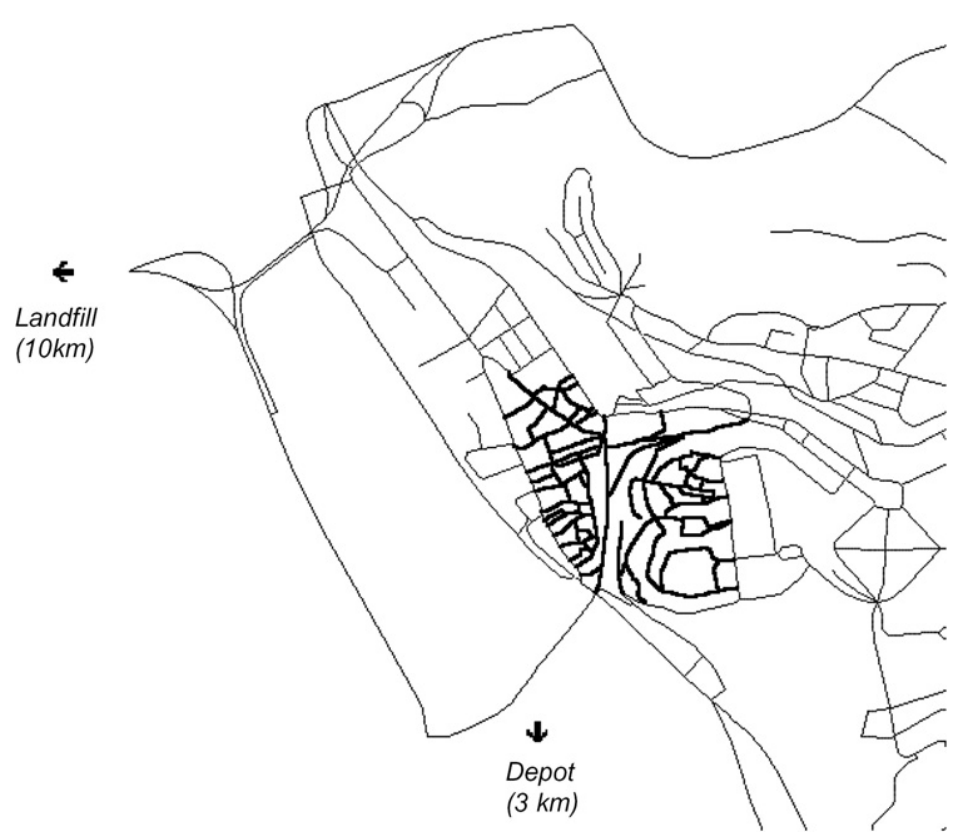

Fig. 3. Coimbra street network with narrow streets highlighted.

Table 1

Summary data for solution to the coimbra trash collection problem

\begin{tabular}{|c|c|c|c|c|c|c|c|c|c|}
\hline \multicolumn{10}{|c|}{ Shift limit: $7 \mathrm{~h} 30 \mathrm{~m}$} \\
\hline & \multicolumn{2}{|c|}{ Totals } & Route 1 & \multicolumn{2}{|c|}{ Route 2} & Truck 1 & \multicolumn{2}{|c|}{ Route 3} & Route 4 \\
\hline Duration & \multicolumn{2}{|c|}{$33 \mathrm{~h} 29 \mathrm{~m}$} & $3 \mathrm{~h} 17 \mathrm{~m}$ & \multicolumn{2}{|c|}{$4 \mathrm{~h} 7 \mathrm{~m}$} & $7 \mathrm{~h} 24 \mathrm{~m}$ & \multicolumn{2}{|c|}{$3 \mathrm{~h} 49 \mathrm{~m}$} & $3 \mathrm{~h} 41 \mathrm{~m}$ \\
\hline Service $(\mathrm{kg})$ & \multicolumn{2}{|c|}{47,227} & 6970 & \multicolumn{2}{|c|}{7000} & 13,970 & \multicolumn{2}{|c|}{6990} & 5012 \\
\hline Route length & \multicolumn{2}{|c|}{480,635} & 36865.2 & \multicolumn{2}{|c|}{63178.3} & 100,043 & \multicolumn{2}{|c|}{44305.2} & 61768.2 \\
\hline Serviced length $(\%)$ & \multicolumn{2}{|c|}{22} & 42 & \multicolumn{2}{|c|}{23} & 30 & \multicolumn{2}{|c|}{34} & 17 \\
\hline \multirow[t]{2}{*}{ Average speed $(\mathrm{km} / \mathrm{h})$} & \multicolumn{2}{|r|}{14} & 11 & & 14 & \multicolumn{2}{|c|}{12} & 17 \\
\hline & Truck 2 & Route 5 & Route 6 & \multicolumn{2}{|c|}{\begin{tabular}{ll}
\multicolumn{2}{c}{15} \\
Truck $3 \quad$ Route 7
\end{tabular}} & Route 8 & Truck 4 & Route 9 & Truck 5 \\
\hline Duration & $7 \mathrm{~h} 29 \mathrm{~m}$ & $4 \mathrm{~h} 37 \mathrm{~m}$ & $2 \mathrm{~h} 53 \mathrm{~m}$ & $7 \mathrm{~h} 29 \mathrm{~m}$ & $4 \mathrm{~h} 13 \mathrm{~m}$ & $3 \mathrm{~h} 15 \mathrm{~m}$ & $7 \mathrm{~h} 28 \mathrm{~m}$ & $3 \mathrm{~h} 37 \mathrm{~m}$ & $3 \mathrm{~h} 37 \mathrm{~m}$ \\
\hline Service $(\mathrm{kg})$ & 12,002 & 6981 & 2529 & 9510 & 6772 & 3041 & 9813 & 1932 & 1932 \\
\hline Route length & 106,073 & 51373.8 & 53,826 & 105,200 & 50563.1 & 59,566 & 110,129 & 59,189 & 59,189 \\
\hline Serviced length (\%) & 24 & 30 & 11 & 20 & 30 & 12 & 20 & 8 & 8 \\
\hline Average speed $(\mathrm{km} / \mathrm{h})$ & 14 & 11 & 19 & 14 & 12 & 18 & 15 & 16 & 16 \\
\hline
\end{tabular}

map can be displayed that shows all of the individual vehicle routes. These are color coded by vehicle and route.

Individual vehicle output includes a map of all of the routes assigned to the vehicle (color coded by specific route) and a map of each route. An example of the latter is shown in Fig. 4, where the dotted lines represent arcs on the route that do not include pickups. Route directions are also generated by the SDSS (e.g., Table 2 shows directions for part of a route). This table also lists the expected accumulated length, load, and time for the route as it progresses from arc to arc. This allows the crew to determine if they are "on-schedule" in terms of time and capacity utilization.

The SDSS also generates route/shift comparison information like that shown in Figs. 5-7. The graph in Fig. 5 shows service distance, non-service distance, and total distance for each route. Notice that there is a high percentage of non-service driving distance. This is a result of the fact that each route must start at the depot (i.e., the first route for each vehicle) or the landfill (for routes other than the first one for each vehicle) and return to the landfill. The last route for each shift must return to the depot after the last drop off. The landfill is $10 \mathrm{~km}$ from the service area, and $15 \mathrm{~km}$ from the depot and the depot is $3 \mathrm{~km}$ from the service area. 


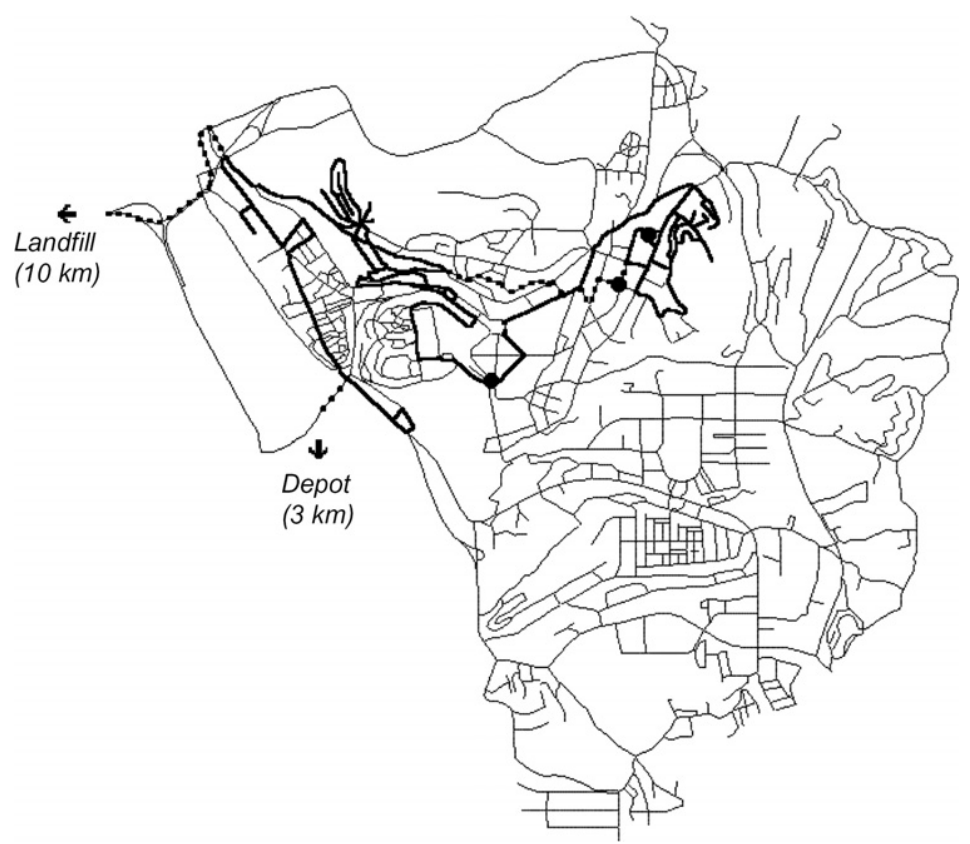

Fig. 4. Route 1 for truck 1 with $7.5 \mathrm{~h}$ shift.

Table 2

Route directions and accumulated load and time for truck 1, route 1

\begin{tabular}{|c|c|c|c|}
\hline Street/Square name & Accumulated distance (m) & Accumulated load (kg) & Accumulated time \\
\hline \multicolumn{4}{|l|}{ Truck 1: route 1} \\
\hline Start at the depot & 3000.0 & 0 & $0 \mathrm{~h} 4 \mathrm{~m}$ \\
\hline Bridge of Santa Clara & 3265.9 & 0 & $0 \mathrm{~h} 5 \mathrm{~m}$ \\
\hline Av. Emidio Navarro & 3613.3 & 145 & $0 \mathrm{~h} 7 \mathrm{~m}$ \\
\hline Av. Emidio Navarro & 3717.3 & 188 & $0 \mathrm{~h} 8 \mathrm{~m}$ \\
\hline R. da Alegria & 3886.5 & 259 & $0 \mathrm{~h} 10 \mathrm{~m}$ \\
\hline R. Olivença & 3965.6 & 292 & $0 \mathrm{~h} 10 \mathrm{~m}$ \\
\hline Av. Emidio Navarro & 4313.0 & 292 & $0 \mathrm{~h} 12 \mathrm{~m}$ \\
\hline Av. Emidio Navarro & 4364.7 & 314 & $0 \mathrm{~h} 13 \mathrm{~m}$ \\
\hline R. da Sota & 4384.7 & 322 & $0 \mathrm{~h} 13 \mathrm{~m}$ \\
\hline R. da Sota & 4412.0 & 333 & $0 \mathrm{~h} 13 \mathrm{~m}$ \\
\hline R. da Sota & 4437.9 & 344 & $0 \mathrm{~h} 14 \mathrm{~m}$ \\
\hline R. da Sota & 4486.4 & 364 & $0 \mathrm{~h} 14 \mathrm{~m}$ \\
\hline R. da Sota & 4520.6 & 378 & $0 \mathrm{~h} 15 \mathrm{~m}$ \\
\hline R. da Sota & 4555.7 & 393 & $0 \mathrm{~h} 15 \mathrm{~m}$ \\
\hline R. da Sota & 4572.7 & 400 & $0 \mathrm{~h} 16 \mathrm{~m}$ \\
\hline R. da Sota & 4597.7 & 410 & $0 \mathrm{~h} 16 \mathrm{~m}$ \\
\hline Av. Fernão Magalhães & 4663.4 & 437 & $0 \mathrm{~h} 17 \mathrm{~m}$ \\
\hline Av. Fernão Magalhães & 4689.0 & 448 & $0 \mathrm{~h} 17 \mathrm{~m}$ \\
\hline Av. Fernão Magalhães & 4721.4 & 461 & $0 \mathrm{~h} 18 \mathrm{~m}$ \\
\hline Av. Fernão Magalhães & 4750.3 & 473 & $0 \mathrm{~h} 18 \mathrm{~m}$ \\
\hline Av. Fernão Magalhães & 4806.2 & 496 & $0 \mathrm{~h} 19 \mathrm{~m}$ \\
\hline Av. Fernão Magalhães & 4887.4 & 530 & $0 \mathrm{~h} 20 \mathrm{~m}$ \\
\hline Av. Fernão Magalhães & 5032.0 & 590 & $0 \mathrm{~h} 21 \mathrm{~m}$ \\
\hline Av. Fernão Magalhães & 5076.6 & 609 & $0 \mathrm{~h} 21 \mathrm{~m}$ \\
\hline Av. Fernão Magalhães & 5099.5 & 619 & $0 \mathrm{~h} 22 \mathrm{~m}$ \\
\hline R. Manuel Rodrigues & 5167.8 & 647 & $0 \mathrm{~h} 22 \mathrm{~m}$ \\
\hline R. Manuel Rodrigues & 5209.9 & 665 & $0 \mathrm{~h} 23 \mathrm{~m}$ \\
\hline $\begin{array}{l}\text { R. Manuel Rodrigues } \\
\vdots\end{array}$ & $\begin{array}{l}5277.3 \\
\vdots\end{array}$ & $\begin{array}{l}693 \\
\vdots\end{array}$ & $\begin{array}{l}0 \text { h } 24 \mathrm{~m} \\
\vdots\end{array}$ \\
\hline
\end{tabular}




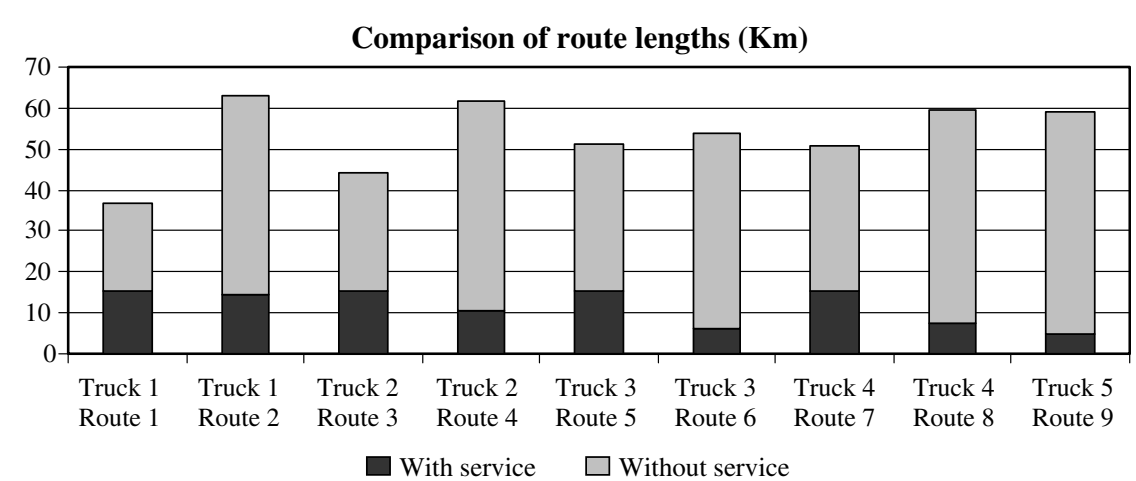

Fig. 5. Comparison of route lengths for the $7.5 \mathrm{~h}$ shift solution.

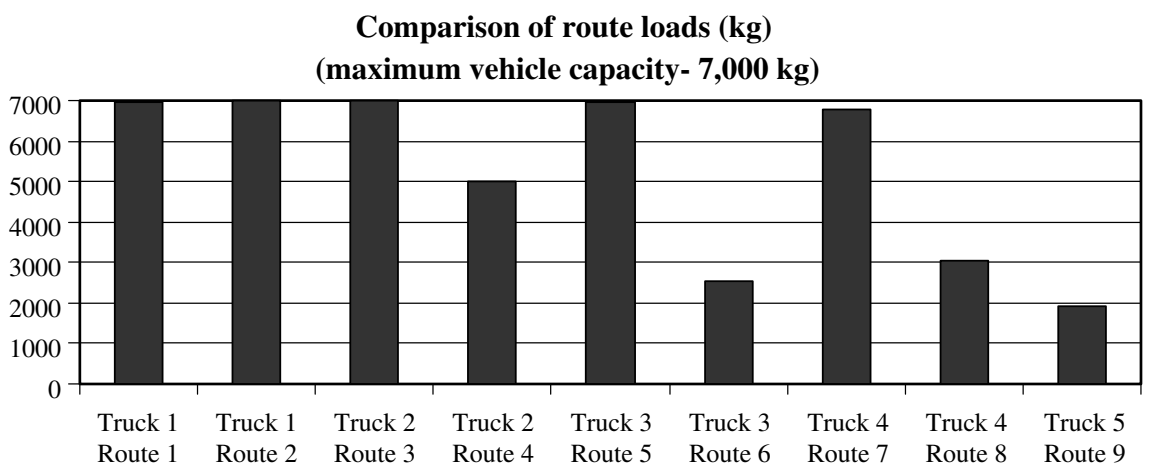

Fig. 6. Comparison of route loads for the $7.5 \mathrm{~h}$ shift solution.

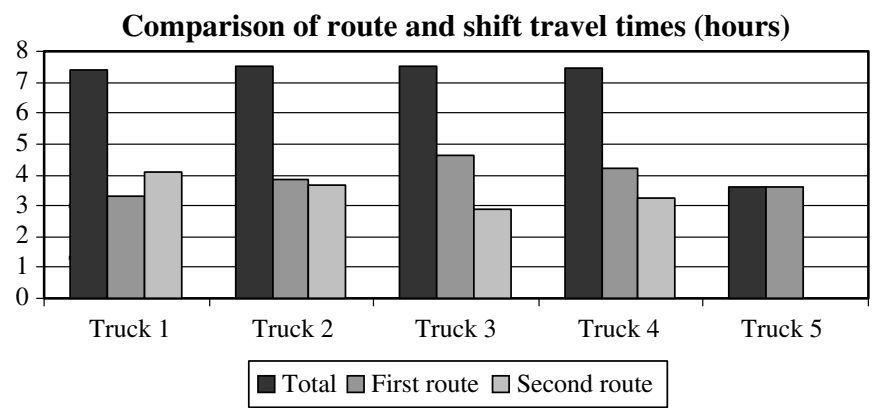

Fig. 7. Comparison of route and truck travel times for the $7.5 \mathrm{~h}$ shift solution.

The total loads for each route are shown in Fig. 6 and the total time for each route and shift is shown in Fig. 7. If major discrepancies occur in route or shift load or time, the route planner can attempt to equalize them by "manually" shifting arcs from one route to another as is explained in the next section.

\subsection{Post solution analysis/long-term planning}

For various reasons, the system planner may want to evaluate alternatives to the routes generated by the heuristic. For example, after the results of the SDSS are analyzed the planner may want to examine the effects of changes to the routes to make them more equal in terms of total load or time. The user can "manually" exchange a pair of serviced arcs or nodes between two selected routes. Assuming that the constraints on 
Table 3

Summary data for sensitivity analysis on total shift time

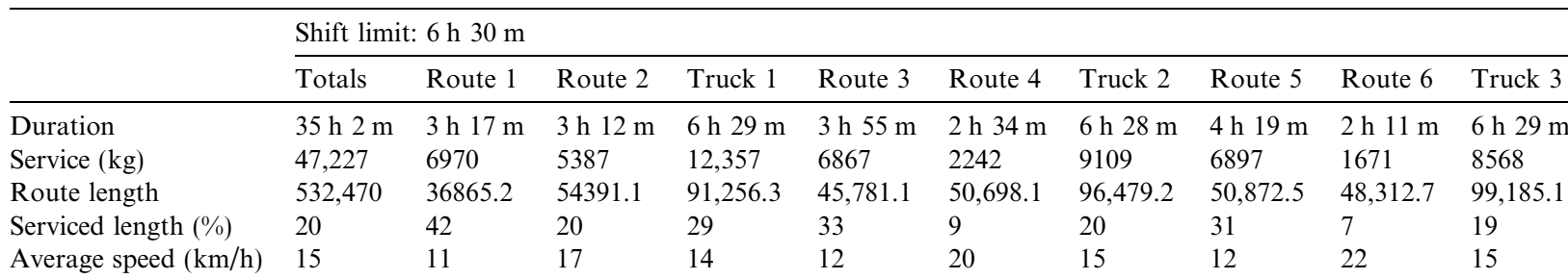

Duration

Service $(\mathrm{kg})$

Route length

Serviced length $(\%)$

Average speed $(\mathrm{km} / \mathrm{h})$

\begin{tabular}{llllllll} 
Route 7 & Route 8 & Truck 4 & Route 9 & Route 10 & Truck 5 & Route 11 & Truck 6 \\
\hline $4 \mathrm{~h} 14 \mathrm{~m}$ & $2 \mathrm{~h} 11 \mathrm{~m}$ & $6 \mathrm{~h} 24 \mathrm{~m}$ & $4 \mathrm{~h} 2 \mathrm{~m}$ & $2 \mathrm{~h} 27 \mathrm{~m}$ & $6 \mathrm{~h} 29 \mathrm{~m}$ & $2 \mathrm{~h} 42 \mathrm{~m}$ & $2 \mathrm{~h} 42 \mathrm{~m}$ \\
6954 & 699 & 7653 & 6617 & 1178 & 7795 & 1745 & 1745 \\
$50,421.7$ & $49,728.3$ & 100,150 & $45,341.6$ & $51,866.1$ & $97,207.7$ & $48,191.7$ & $48,191.7$ \\
31 & 3 & 17 & 34 & 5 & 19 & 9 & 9 \\
12 & 23 & 16 & 11 & 21 & 15 & 18 & 18
\end{tabular}

Shift limit: $7 \mathrm{~h}$

\begin{tabular}{|c|c|c|c|c|c|c|c|c|c|c|}
\hline & Totals & Route 1 & Route 2 & Truck 1 & Route 3 & Route 4 & Truck 2 & Route 5 & Route 6 & Truck 3 \\
\hline Duration & $32 \mathrm{~h} 50 \mathrm{~m}$ & $3 \mathrm{~h} 17 \mathrm{~m}$ & $3 \mathrm{~h} 43 \mathrm{~m}$ & $6 \mathrm{~h} 59 \mathrm{~m}$ & $3 \mathrm{~h} 49 \mathrm{~m}$ & $3 \mathrm{~h} 10 \mathrm{~m}$ & $6 \mathrm{~h} 59 \mathrm{~m}$ & $3 \mathrm{~h} 50 \mathrm{~m}$ & $3 \mathrm{~h} 8 \mathrm{~m}$ & $6 \mathrm{~h} 58 \mathrm{~m}$ \\
\hline Service $(\mathrm{kg})$ & 47,227 & 6970 & 6229 & 13,199 & 6995 & 3723 & 10,718 & 6992 & 2857 & 9849 \\
\hline Route length & 472,740 & $36,865.2$ & $59,115.5$ & $95,980.7$ & $44,216.2$ & $57,236.4$ & 101,453 & 46,163 & $56,576.2$ & 102,739 \\
\hline Serviced length $(\%)$ & 22 & 42 & 21 & 29 & 36 & 14 & 24 & 31 & 11 & 20 \\
\hline \multirow[t]{2}{*}{ Average speed $(\mathrm{km} / \mathrm{h})$} & 14 & 11 & 16 & 14 & 12 & 18 & 15 & 12 & 18 & 15 \\
\hline & & Route 7 & & Route 8 & & Truck 4 & & Route 9 & & Truck 5 \\
\hline Duration & & $4 \mathrm{~h} 3 \mathrm{~m}$ & & $2 \mathrm{~h} 55 \mathrm{~m}$ & & $6 \mathrm{~h} 58 \mathrm{~m}$ & & $4 \mathrm{~h} 55 \mathrm{~m}$ & & $4 \mathrm{~h} 55 \mathrm{~m}$ \\
\hline Service (kg) & & 6833 & & 2150 & & 8983 & & 4478 & & 4478 \\
\hline Route length & & $45,451.9$ & & $56,706.9$ & & 102,159 & & $70,408.9$ & & $70,408.9$ \\
\hline Serviced length $(\%)$ & & 34 & & 9 & & 20 & & 15 & & 15 \\
\hline Average speed $(\mathrm{km} / \mathrm{h})$ & & 11 & & 19 & & 15 & & 14 & & 14 \\
\hline
\end{tabular}

Shift limit: 7 h $30 \mathrm{~m}$

\begin{tabular}{|c|c|c|c|c|c|c|c|c|c|c|}
\hline & Totals & Route 1 & Route 2 & Truck 1 & Route 3 & Route 4 & Truck 2 & Route 5 & Route 6 & $\overline{\text { Truck } 3}$ \\
\hline Dura & $33 \mathrm{~h} 29 \mathrm{~m}$ & $3 \mathrm{~h} 17 \mathrm{~m}$ & $4 \mathrm{~h} 7 \mathrm{~m}$ & $7 \mathrm{~h} 24 \mathrm{~m}$ & $3 \mathrm{~h} 49 \mathrm{~m}$ & $3 \mathrm{~h} 41 \mathrm{~m}$ & $7 \mathrm{~h} 29 \mathrm{~m}$ & $4 \mathrm{~h} 37 \mathrm{~m}$ & $2 \mathrm{~h} 53 \mathrm{~m}$ & $7 \mathrm{~h} 29 \mathrm{~m}$ \\
\hline Service $(\mathrm{kg})$ & 47,227 & 6970 & 7000 & 13,970 & 6990 & 5012 & 12,002 & 6981 & 2529 & 9510 \\
\hline Route length & 480,635 & $36,865.2$ & $63,178.3$ & 100,043 & $44,305.2$ & $61,768.2$ & 106,073 & $51,373.8$ & 53,826 & 105,200 \\
\hline Serviced length $(\%)$ & 22 & 42 & 23 & 30 & 34 & 17 & 24 & 30 & 11 & 20 \\
\hline Average speed $(\mathrm{km} / \mathrm{h})$ & 14 & 11 & 15 & 14 & 12 & 17 & 14 & 11 & 19 & 14 \\
\hline
\end{tabular}

Duration

Service (kg)

Route length

Serviced length (\%)

Average speed $(\mathrm{km} / \mathrm{h})$

\begin{tabular}{lllll} 
Route 7 & Route 8 & Truck 4 & Route 9 & Truck 5 \\
\hline $4 \mathrm{~h} 13 \mathrm{~m}$ & $3 \mathrm{~h} 15 \mathrm{~m}$ & $7 \mathrm{~h} 28 \mathrm{~m}$ & $3 \mathrm{~h} 37 \mathrm{~m}$ & $3 \mathrm{~h} 37 \mathrm{~m}$ \\
6772 & 3041 & 9813 & 1932 & 1932 \\
$50,563.1$ & 59,566 & 110,129 & 59,189 & 59,189 \\
30 & 12 & 20 & 8 & 8 \\
12 & 18 & 15 & 16 & 16
\end{tabular}

Shift limit: $8 \mathrm{~h}$

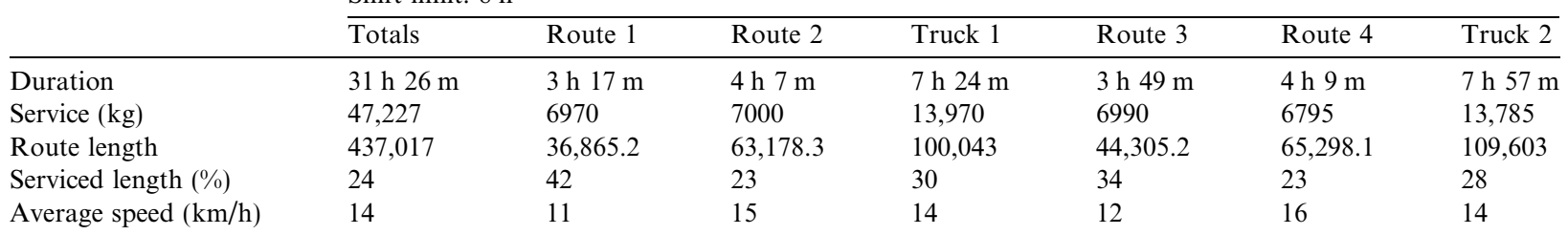

Duration

Service $(\mathrm{kg})$

Route length

Serviced length (\%)

Average speed $(\mathrm{km} / \mathrm{h})$

\begin{tabular}{llllll} 
Route 5 & Route 6 & Truck 3 & Route 7 & Route 8 & Truck 4 \\
\hline $4 \mathrm{~h} 37 \mathrm{~m}$ & $3 \mathrm{~h} 23 \mathrm{~m}$ & $7 \mathrm{~h} 59 \mathrm{~m}$ & $4 \mathrm{~h} 29 \mathrm{~m}$ & $3 \mathrm{~h} 35 \mathrm{~m}$ & $8 \mathrm{~h} 4 \mathrm{~m}$ \\
6981 & 3027 & 10,008 & 6669 & 2795 & 9464 \\
$51,373.8$ & $59,261.4$ & 110,635 & $53,233.8$ & $63,500.8$ & 116,735 \\
30 & 12 & 20 & 29 & 10 & 19 \\
11 & 17 & 14 & 12 & 18 & 14
\end{tabular}


Table 3 (continued)

\begin{tabular}{|c|c|c|c|c|c|c|c|c|}
\hline & \multicolumn{8}{|c|}{ Shift limit: $8 \mathrm{~h} 30 \mathrm{~m}$} \\
\hline & Totals & Route 1 & Route 2 & Route 3 & Truck 1 & Route 4 & Route 5 & $\overline{\text { Truck } 2}$ \\
\hline Duration & $32 \mathrm{~h} 33 \mathrm{~m}$ & $3 \mathrm{~h} 17 \mathrm{~m}$ & $3 \mathrm{~h} 42 \mathrm{~m}$ & $1 \mathrm{~h} 30 \mathrm{~m}$ & $8 \mathrm{~h} 29 \mathrm{~m}$ & $3 \mathrm{~h} 45 \mathrm{~m}$ & $4 \mathrm{~h} 19 \mathrm{~m}$ & $8 \mathrm{~h} 4 \mathrm{~m}$ \\
\hline Service $(\mathrm{kg})$ & 47,227 & 6970 & 7000 & 541 & 14,511 & 7000 & 6964 & 13964 \\
\hline Route length & 464,797 & $36,865.2$ & $48,129.2$ & $41,389.5$ & 126,384 & 43850.9 & 67233.3 & 111084 \\
\hline Serviced length (\%) & 22 & 42 & 30 & 3 & 25 & 34 & 22 & 27 \\
\hline \multirow[t]{2}{*}{ Average speed $(\mathrm{km} / \mathrm{h})$} & 14 & 11 & 13 & 28 & 15 & 12 & 16 & 14 \\
\hline & \multicolumn{2}{|c|}{ Route 6} & Route 7 & Truck 3 & \multicolumn{2}{|l|}{ Route 8} & oute 9 & Truck 4 \\
\hline Duration & \multicolumn{2}{|c|}{$4 \mathrm{~h} 16 \mathrm{~m}$} & $4 \mathrm{~h} 13 \mathrm{~m}$ & $8 \mathrm{~h} 28 \mathrm{~m}$ & \multicolumn{2}{|l|}{$4 \mathrm{~h} 46 \mathrm{~m}$} & $45 \mathrm{~m}$ & $7 \mathrm{~h} 31 \mathrm{~m}$ \\
\hline Service $(\mathrm{kg})$ & \multirow{2}{*}{$\begin{array}{l}6619 \\
47,56\end{array}$} & \multicolumn{2}{|c|}{4900} & 11,519 & 6741 & & & 7233 \\
\hline Route length & & & 07.9 & 113,872 & $56,825.6$ & & 531.2 & 113,457 \\
\hline Serviced length $(\%)$ & 32 & $1^{1}$ & & 23 & 28 & 2 & & 15 \\
\hline Average speed $(\mathrm{km} / \mathrm{h})$ & 11 & 1 & & 13 & 12 & 2 & & 15 \\
\hline & Shift limit: & & & & & & & \\
\hline & Totals & Route 1 & Route 2 & Route 3 & Truck 1 & Route 4 & Route 5 & Truck 2 \\
\hline Duration & $31 \mathrm{~h} 20 \mathrm{~m}$ & $3 \mathrm{~h} 17 \mathrm{~m}$ & $3 \mathrm{~h} 42 \mathrm{~m}$ & $1 \mathrm{~h} 59 \mathrm{~m}$ & $8 \mathrm{~h} 57 \mathrm{~m}$ & $3 \mathrm{~h} 36 \mathrm{~m}$ & $5 \mathrm{~h} 18 \mathrm{~m}$ & $8 \mathrm{~h} 53 \mathrm{~m}$ \\
\hline Service $(\mathrm{kg})$ & 47,227 & 6970 & 7000 & 1043 & 15,013 & 7000 & 6993 & 13,993 \\
\hline Route length & 435,854 & $36,865.2$ & $48,129.2$ & $46,263.1$ & 131,257 & 42175.1 & 76484.5 & 118660 \\
\hline Serviced length $(\%)$ & 24 & 42 & 30 & 5 & 25 & 37 & 20 & 26 \\
\hline Average speed $(\mathrm{km} / \mathrm{h})$ & 14 & 11 & 13 & 23 & 15 & 12 & 14 & 13 \\
\hline & & 6 & Route 7 & & Truck 3 & Rou & & Truck 4 \\
\hline Duration & & $8 \mathrm{~m}$ & $4 \mathrm{~h} 54 \mathrm{~m}$ & & $8 \mathrm{~h} 21 \mathrm{~m}$ & $5 \mathrm{~h}$ & & $5 \mathrm{~h} 7 \mathrm{~m}$ \\
\hline Service $(\mathrm{kg})$ & 68 & & 6995 & & 13,824 & 4397 & & 4397 \\
\hline Route length & & 8.2 & $70,521.3$ & & 112,799 & 73,1 & & $73,137.6$ \\
\hline Serviced length $(\%)$ & 35 & & 22 & & 27 & 14 & & 14 \\
\hline Average speed $(\mathrm{km} / \mathrm{h})$ & 12 & & 14 & & 13 & 14 & & 14 \\
\hline
\end{tabular}

vehicle capacity and time are not violated by the exchange, it will be executed by the SDSS using a heuristic algorithm. The corresponding routes are redrawn, inserting an arc and deleting another arc in each route. The inserted arc is connected to its new route using shortest paths. The deletion of the other arc may require the creation of a substitution shortest path link in the route. All of this done automatically once the user has identified the arcs or nodes to be exchanged.

The SDSS can also be used for sensitivity and what-if analyses. For example, how would changes in vehicle capacity or shift times affect the number of vehicles and routes required? We analyzed the tradeoffs between shift time and the number of vehicles required by solving the problem with shift limits of $6 \mathrm{~h} 30 \mathrm{~min}, 7 \mathrm{~h}, 7 \mathrm{~h}$ $30 \mathrm{~min}, 8 \mathrm{~h}, 8 \mathrm{~h} 30 \mathrm{~min}$, and $9 \mathrm{~h}$. Note, we allowed the shifts to extend $5 \mathrm{~min}$ beyond the stated time limits if this would allow a route to service an additional arc before going to the landfill. Summaries of these solutions are shown in Table 3 and Fig. 8.

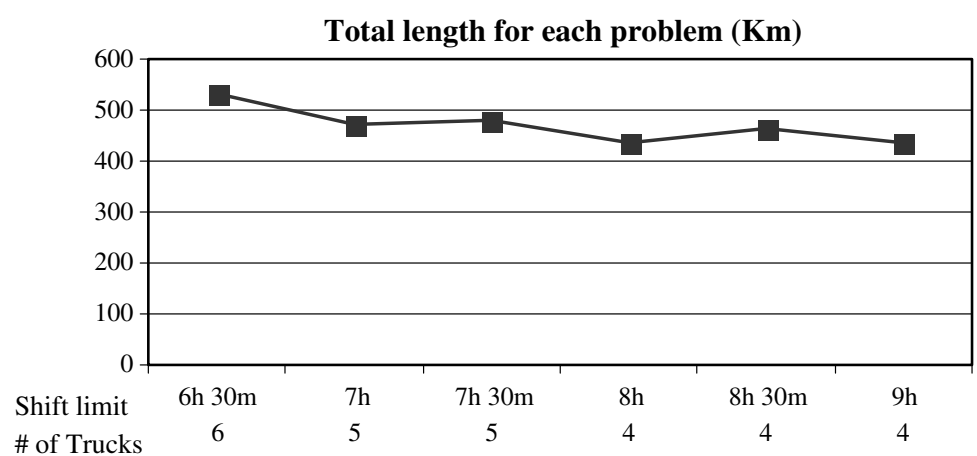

Fig. 8. Summary of sensitivity analysis on total shift time. 
This type of what-if analysis is possible as individual solutions to the Coimbra network took less than 2 min to generate on a $2 \mathrm{GHz}$ Pentium IV computer.

This analysis demonstrates that by utilizing $8 \mathrm{~h}$ shifts, the network could be served by four vehicles instead of the five required by the current $7 \mathrm{~h} 30 \mathrm{~min}$ shifts. This change would require paying overtime to three crews (i.e., shifts 2-4) but would require one less crew and one less vehicle, which cost $€ 100,000$ to purchase. Planners can now analyze the cost and reliability issues (i.e., less flexibility in dealing with demand fluctuation as there is less slack in the system) associated with such a change.

\section{Summary and conclusions}

In this article, we address a real-world multi-vehicle, multi-stop routing problem: trash collection. We call the underlying problem the constrained capacitated arc routing problem (C-CARP) as it is a more constrained version of the capacitated arc routing problem (CARP) (Golden and Wong, 1981). C-CARP is a generalization of CARP in that it can accommodate one-way streets; demand located at nodes of the network as well as along arcs of the network; prohibited turns; and vehicle time (as well as capacity) constraints, among other realistic routing considerations.

A spatial decision support system (SDSS) was designed to analyze the C-CARP. Given that such problems are computationally intractable, solution heuristics were designed and embedded in the SDSS to determine the number of vehicles and routes to employ as well as design the individual routes. Important design considerations included user-friendly inputs (e.g., changes to the network) and outputs (e.g., route maps) for use by system planners and vehicle drivers. A commercial geographical information system (ESRI, 1996) was incorporated into the SDSS to address these considerations.

The SDSS was tested in the City of Coimbra, Portugal. The results indicate that a multiple-vehicle routing SDSS based upon spreadsheet data input, efficient solution heuristics, and GIS can be used to analyze and solve extremely complicated multiple-vehicle routing problems and provide system analysts with pertinent data and maps regarding total system performance as well as data, maps, and directions for the drivers for their individual routes. In addition, the SDSS enables planners to analyze the benefits and costs of possible changes to system parameters such as vehicle capacity and shift duration constraints.

Dablanc (2007) concluded that "...the large majority of cities have not yet found adequate solutions to help optimize the urban movement of goods". Certainly, the same is true for many cities in other continents. This research has shown that a user-friendly SDSS can be designed to analyze complex urban transportation problems. Although the application presented in this paper is case specific, the GIS-based SDSS is applicable to many public and private sector multiple-vehicle routing problems. The system can be used for short-term analysis (e.g., the design of daily vehicle routes) and long-term analysis (e.g., how many vehicles to operate).

\section{Appendix}

The route generation heuristic presented in the text requires the determination of shortest paths. Labeling algorithms (e.g., Dijkstra, 1959) can solve shortest path problems very efficiently. However, these algorithms require that each node have exactly one label that is the label of a predecessor node plus an arc cost. Unfortunately, this causes problems in many networks such as Coimbra's where turn prohibitions exist. Consider the example in Fig. A-1 where the source node is $s$ and all arcs have equal costs, the shortest path from $s$ to node 1 is $(s, 1)$. The shortest path from $s$ to $t$ is not $s \rightarrow 1 \rightarrow t$ because a left turn restriction prohibits a turn from $\operatorname{arc} a_{1}$ to $\operatorname{arc} a_{3}$. As a result of this turn prohibition, node 1 appears two times in the shortest path from node $s$ to node $t(s \rightarrow 1 \rightarrow 2 \rightarrow 1 \rightarrow t)$ as is shown in Fig. A-2 (note, node 2 is a "roundabout" or "circle" which allow a vehicle to make a U-turn). Consequently, node 1 requires two labels that are not possible in traditional shortest path algorithms.

To overcome this problem, the algorithm must label the arcs on the path rather than nodes on it. The resulting shortest path from node $s$ to node $t$ and it's labeling scheme $\left(a_{0} \rightarrow a_{1} \rightarrow a_{4} \rightarrow a_{5} \rightarrow a_{3}\right)$ are shown in Fig. A-3 where $a_{0}$ is a "dummy arc" representing the starting node, $s$. As this example demonstrates, nodes may be entered more than once in shortest paths in networks with turn prohibitions. However, a directed arc will never appear more than one time in a shortest path unless it has a negative cost which is not the case here. 


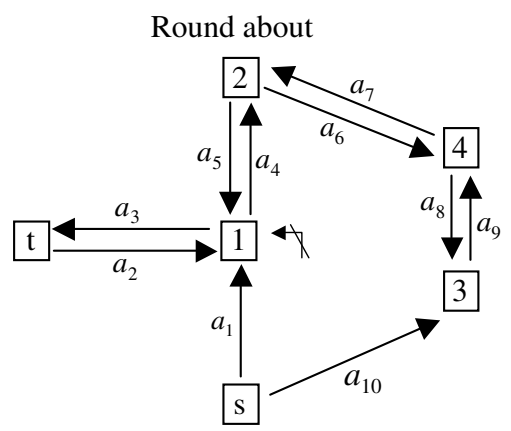

Fig. A-1. Network with a prohibited turn.

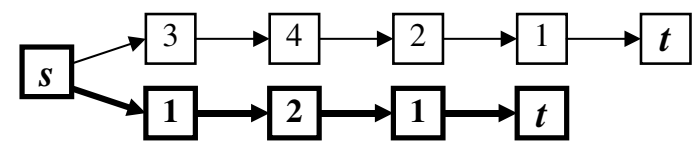

Fig. A-2. Paths from node $s$ to node $t$ based on nodes as predecessors.

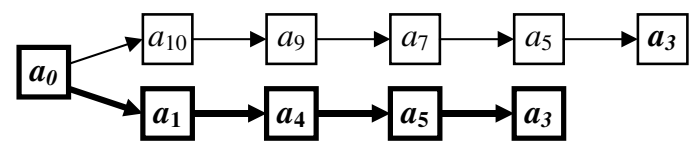

Fig. A-3. Paths from $s$ to $t$ based on arcs as predecessors.

Consequently, the arc labeling algorithm identifies all feasible shortest paths and allows nodes to be entered more than one time if is efficient or necessary to so because of restricted turns. The Buckets "basic implementation" (Dial, 1969) of the Dijkstra algorithm (1959) was used to solve the shortest path problems because of its coding simplicity and efficiency.

\section{References}

Alçada-Almeida, L., Tralhão, L., Santos, L., Coutinho-Rodrigues, J., in press. A multiobjective p-median modeling approach to locating shelters and evacuation routes for emergencies in urban areas. Geographical Analysis.

Belenguer, J.M., Benavent, E., Lacomme, P., Prins, C., 2006. Lower and upper bounds for the mixed capacitated arc routing problem. Computers and Operations Research 33 (12), 3363-3383.

Chapleau, L., Ferland, J.A., Lapalme, G., Rousseau, J.M., 1984. A parallel insert method for the capacitated arc routing problem. Operations Research Letters 3 (2), 95-99.

Christofides, N., 1973. The optimum traversal of a graph. Omega 1 (6), 719-732.

Church, R.L., 2002. Geographical information systems and location science. Computers and Operations Research 29 (6), $541-562$.

Coutinho-Rodrigues, J., Rodrigues, N., Clímaco, J., 1993. Solving an urban routing problem using heuristics - a successful case study. JORBEL - Belgian Journal of Operations Research, Statistics and Computer Science 33 (1-2), 19-32.

Coutinho-Rodrigues, J., Current, J., Climaco, J., Ratick, S., 1997. An interactive spatial decision support system for multiobjective HAZMAT location-routing problems. Transportation Research Record 1602, 101-109.

Dablanc, L., 2007. Goods transport in large European cities: difficult to organize, difficult to modernize. Transportation Research Part A 41 (3), 280-285.

Dantzig, G.B., Fulkerson, D.R., Johnson, S.M., 1954. Solution of a large-scale traveling salesman problem. Operations Research 2, 393410 .

Dial, R., 1969. Algorithm 360: shortest path forest with topological ordering. Communications of the ACM 12, $632-633$.

Dijkstra, E.W., 1959. A note on two problems with connection with graphs. Numerische Mathematik 1 (5), $269-271$.

ESRI, 1996. ArcView ${ }^{\circledR}$ GIS: The Geographic Information Systems for Everyone. Environmental Systems Research Institute Inc. (ESRI), Redlands, CA.

Garey, M.R., Johnson, D.S., 1979. Computers and Intractability: A Guide to the Theory of NP-completeness. W.H. Freeman, New York.

Golden, B.L., Wong, R.T., 1981. Capacitated arc routing problems. Networks 11, 305-315. 
Golden, B.L., DeArmon, J., Baker, E.K., 1983. Computational experiments with algorithms for a class of routing problems. Computers and Operations Research 10 (1), 47-59.

Jha, M.K., Schonfeld, P., 2004. A highway alignment optimization model using geographic information systems. Transportation Research Part A 38 (6), 455-481.

Kwan, M.K., 1962. Graphic programming using odd or even points. Chinese Mathematics 1 (3), $273-277$.

Lacomme, P., Prins, C., Ramdane-Chérif, W., 2004. Competitive memetic algorithms for arc routing problems. Annals of Operations Research 131, 159-185.

MacroSys Research and Technology, 2005. Logistics Costs and US Gross Domestic Product. Federal Highway Administration Department of Transportation, August 25, 2005. <http://ops.fhwa.dot.gov/freight/freight_analysis/econ_methods/lcdp_rep/ index.htm>.

Magnanti, T.L., Wong, R.T., 1984. Network design and transportation planning: models and algorithms. Transportation Science 18 (1), $1-55$.

Maria, J., Coutinho-Rodrigues, J., Current, J., 2005. Interactive destination marketing system for small and medium-sized tourism destinations. Tourism: An Interdisciplinary Journal 53, 45-54.

Namkoong, S., Rho, J.-H., Choi, J.-U., 1998. Development of the tree-based link labeling algorithm for optimal path-finding in urban transportation networks. Mathematical Computer Modelling 27 (9), 51-65.

Pearn, W.L., 1984. The capacitated chinese postman problem. PhD Thesis. University of Maryland, USA

Simao, A., Coutinho-Rodrigues, J., Current, J., 2004. A management information system for urban water supply networks. ASCE Journal of Infrastructure Systems 10 (4), 176-180.

Thill, J.-C., 2000. Geographic information systems for transportation in perspective. Transportation Research Part C 8, 3-12.

Ülengin, F., Önsel, Ş., Topçu, Y., Aktaş, E., Özgur, K., 2007. An integrated transportation decision support system for transportation policy decisions: the case of Turkey. Transportation Research Part A 41 (1), 80-97. 